Abstracta Iranica Abstracta Iranica

Revue bibliographique pour le domaine irano-aryen

Volume 34-35-36 | 2017

Comptes rendus des publications de 2011-2013

\title{
Vito Messina, Jafar Mehr Kian. Ricognizione dei relievi partici d'Elimaide. La piana di Izeh-Malamir
}

\section{Rémy Boucharlat}

\section{(2) OpenEdition}

\section{Journals}

\section{Édition électronique}

URL : http://journals.openedition.org/abstractairanica/41496

DOI : 10.4000/abstractairanica.41496

ISSN : 1961-960X

Éditeur :

CNRS (UMR 7528 Mondes iraniens et indiens), Éditions de l'IFRI

\section{Référence électronique}

Rémy Boucharlat, «Vito Messina, Jafar Mehr Kian. Ricognizione dei relievi partici d'Elimaide. La piana di Izeh-Malamir », Abstracta Iranica [En ligne], Volume 34-35-36 | 2017, document 4, mis en ligne le 15 juillet 2016, consulté le 05 octobre 2020. URL : http://journals.openedition.org/abstractairanica/41496 ; DOI : https://doi.org/10.4000/abstractairanica.41496

Ce document a été généré automatiquement le 5 octobre 2020.

Tous droits réservés 


\title{
Vito Messina, Jafar Mehr Kian. Ricognizione dei relievi partici d'Elimaide. La piana di Izeh-Malamir
}

\author{
Rémy Boucharlat
}

\section{RÉFÉRENCE}

Vito Messina, Jafar Mehr Kian. « Ricognizione dei relievi partici d'Elimaide. La piana di Izeh-Malamir ». Vicino \& Medio Oriente, 15, 2011, p. 215-231.

1 Cet article donne un résumé des trois campagnes 2008-2010 sur le programme conjoint d'étude des bas-reliefs d'Elymaïde, principalement d'époque parthe ; il fait suite au rapport des mêmes auteurs ( The Iranian-Italian joint expedition in Khuzistan Hung-e Azhdar: 1st campaign (2008) ». Parthica, 12, 2010, p. 31-45). La mission a entrepris le relevé précis par scanner laser3D de ces reliefs, principalement celui de Hūnng-e Aždar, particulièrement discuté puisque l'on sait maintenant qu'il appartient à deux périodes, à gauche un cavalier de profil, peut-être le prince Kamnaskires d'Elymaïde (milieu du $\mathrm{II}^{\mathrm{e}} \mathrm{s}$. av. J.-C.), à droite quatre personnages de face qui seraient à dater entre le $1^{\mathrm{er}}$ et le début du III ${ }^{\mathrm{e}} \mathrm{s}$. de notre ère (en dernier lieu Invernizzi dans Mesopotamia 23, 1998, Abs. Ir. 20-21, c.r. $\mathrm{n}^{\circ}$ 195). Les nouvelles technologies permettent une étude beaucoup plus détaillée des formes et du relief des images, ainsi que des traces d'outils. Une inscription courte et fragmentaire, découverte ainsi, n'a pu être lue. Trois sondages de quelques mètres carrés au pied du relief ont montré des couches très bouleversées mais quelques structures en pierre in situ. 


\section{AUTEURS}

RÉMY BOUCHARLAT

CNRS, Lyon 